\title{
Prevalence of echinococcosis and Taenia hydatigena cysticercosis in slaughtered small ruminants at the livestock-wildlife interface areas of Ngorongoro, Tanzania
}

\author{
M. B. Miran ${ }^{1}$, A. A. Kasuku² and E. S. Swai ${ }^{3}$
}

1. Department of Livestock, Ngorongoro District Council, P. O. Box 1, Loliondo, Tanzania; 2. Department of Microbiology and Parasitology, Faculty of Veterinary Medicine, Sokoine University of Agriculture, P.O. Box 3015, Morogoro, Tanzania; 3. Ministry of Agriculture, Livestock and Fisheries, P. O. Box 9152, Dar-es-Salaam, Tanzania.

Corresponding author: E. S. Swai, e-mail: esswai@gmail.com,

Co-authors: MBM: miranbmiran@yahoo.com, AAK: kassuku@suanet.ac.tz

Received: 25-10-2016, Accepted: 27-02-2017, Published online: 19-04-2017

doi: 10.14202/vetworld.2017.411-417 How to cite this article: Miran MB, Kasuku AA, Swai ES (2017) Prevalence of echinococcosis and Taenia hydatigena cysticercosis in slaughtered small ruminants at the livestock-wildlife interface areas of Ngorongoro, Tanzania, Veterinary World, 10(4):411-417.

\begin{abstract}
Aim: Echinococcosis or hydatidosis (due to the larval stage of Echinococcus spp.) and cysticercosis (due to the larval stage of Taenia hydatigena) pose a significant economic losses due to slaughter condemnation and risk to public health in developing countries such as Tanzania where sanitation is poor and people live in close proximity with each other and with animals. This study was conducted to determine the prevalence of and to identify the predisposing factors for echinococcosis and cysticercosis in sheep and goats at three slaughter slabs located in the livestock-wildlife interface areas of Ngorongoro, Tanzania.
\end{abstract}

Materials and Methods: A cross-sectional based survey was conducted, from January 2013 to April 2013, whereby a total of 180 animals comprising 90 goats and 90 sheep of both sexes were examined at postmortem for the evidence of larval stages of Echinococcus spp. (hydatid cyst) and T. hydatigena (Cysticercus tenuicollis) through visual inspection, incision and palpation of organs and viscera.

Results: The prevalence of echinococcosis was $22.2 \%$ and $16.6 \%$, in goats and sheep, respectively, while the overall infection rates for cysticercosis were $61.1 \%$ in goats and $42.2 \%$ in sheep. The result of this study revealed that goats and sheep in Malambo slaughter slab had significantly higher prevalence of T. hydatigena (C. tenuicollis) and hydatid cysts $(\mathrm{p}<0.05)$ compared to other slab points. T. hydatigena $($ C. tenuicollis) cysts were more frequently detected in the omentum than other visceral organs among the animals examined.

Conclusion: In conclusion, the observed high prevalence of the two metacestodes larval stages leads to high condemnation rates of edible offals and raises significant public health concerns. This underscores for the need to undertake more extensive epidemiological investigations to better determine the causal factors, economic impact, and public health importance of the disease in this livestock-wildlife interface setting.

Keywords: cysticercosis, echinococcosis, small ruminants, Tanzania, wildlife interface.

\section{Introduction}

Goats and sheep represent the second and third largest proportion of the livestock population in Tanzania, respectively. Tanzania's small ruminant wealth in 2008 included 15.1 million goats and 5.7 million sheep [1]. More than $99 \%$ of this livestock are kept in low-input low-output systems, owned and managed by $1,732,863$ low income mixed and pastoral households who operate under traditional husbandry system, often with little or no access to informed and relevant animal production advice or reliable veterinary services.

Cestodes of the family Taeniidae infect carnivores as the definitive host and are transmitted to a wide

Copyright: Miran, et al. Open Access. This article is distributed under the terms of the Creative Commons Attribution 4.0 International License (http://creativecommons.org/licenses/by/4.0/), which permits unrestricted use, distribution, and reproduction in any medium, provided you give appropriate credit to the original author(s) and the source, provide a link to the Creative Commons license, and indicate if changes were made. The Creative Commons Public Domain Dedication waiver (http://creativecommons.org/ publicdomain/zero/1.0/) applies to the data made available in this article, unless otherwise stated. range of intermediate host species where they cause hydatidosis and cysticercossis. Cysticercus tenuicollis and hydatid cyst are larval stages of the canine tapeworm Taenia hydatigena and Echinococcus granulosus, respectively. The two cestodes are found in a large number of hosts throughout the world [2-5]. The cystic echinococcosis (also called hydatidosis) and T. hydatigena cysticercosis (due to C. tenuicollis) are widespread parasitic diseases infecting a large number of wild and domestic animals and humans and are considered as one of the major causes of economic losses and productivity of livestock in both the developing and industrialized world [6-8]. The intermediate host contracts infection by ingesting proglottids or eggs passed in dog feces that contaminate the pasture or feeding areas [3]. Cysts can be spread by other canids such as wolves, jackals, and foxes which are definitive hosts [9]. The loss due to the condemnation of organs by hydatid and $C$. tenuicollis cysts in small ruminants is significant in countries, such as Tanzania, where there are low standards of sanitation, unregulated 
home slaughter and close contact between people and animals especially in pastoral communities [10].

Although numerous surveys on the prevalence have been reported in different parts of the world $[10,11]$, there are a very limited number of studies on $C$. tenuicollis and hydatid cyst in Tanzania $[12,13]$; no comprehensive study has been conducted of these parasites in sheep and goats in the livestock-wildlife interface. Analysis of the factors influencing the occurrence of these parasites might provide further insight into the epidemiology of $C$. tenuicollis and hydatid cyst infections. Because of the scarcity of such data in the literature, we aimed by the present work, to determine the prevalence of hydatidosis and cysticercosis in sheep and goats as well as to explore the influence of sex, age and slaughter slab location as determinants of infection.

\section{Materials and Methods}

\section{Ethical approval}

Permission to carry out this study was granted by the District Executive Director of Ngorongoro. The protocols for this study were approved by the Sokoine University of Agriculture, Morogoro, Ethics Committee. Before starting data collection, and after explaining the purpose and importance of the study, the consent was obtained from each of the trade stock owners to conduct the necessary carcass examinations. Operating procedures regarding the safety of researchers, community and environment were strictly adhered to at all stages of sample collection, handling and processing.

\section{Study area}

This study was conducted in Ngorongoro, the largest of the seven districts in Arusha region, northern Tanzania. The district lies between longitude $35^{\prime} 30^{\circ}$ and $36^{\prime} 23^{\circ} \mathrm{E}$ and latitude $02^{\prime} 45^{\circ}$ and $4^{\prime} 01^{\circ} \mathrm{S}$ covering an area of $14,036 \mathrm{~km}^{2}$ (Figure-1). Geographically, the district is bordered by Kenya to the north, Serengeti National Park to the west, Longido and Monduli Districts to the east and Karatu District to the south. The district has heterogeneous physical and climatic features varying from cool (Loliondo and Ngorongoro Conservation Area Authority) highlands in the North and South, respectively, to semi-arid plains in the central West and South. Administratively, it is divided into 3 divisions, 21 wards and 43 registered villages and subvillages. Other climate and weather related information are described in detail by Miran et al. [14].

\section{Participating slaughter slab and population of interest}

Three slaughter slabs located in Waso, Malambo and Endulen villages were selected in collaboration with the government livestock extension and administration officers. Selection criterion of the villages was based on the high numbers of slaughter of sheep and goats at these sites. Only animals originating from within the village and the surrounding area where a particular slaughter slab is located were examined during the study. To avoid or minimize the inclusion of slaughtered animals originating from outside the study area, animals slaughtered during livestock market days were excluded in the study. The study was conducted from January 2013 to April 2013. In each month, about 50 animals (25 sheep and 25 goats) of both sexes and of different age groups (classified as $\leq 1$ to $1, \geq 1$ to $2, \geq 2$ years) slaughtered at three local slaughter slabs (Waso, Malambo, and Endulen) were randomly selected and individually identified.

\section{Parasitological examination}

The presences of tape-worm metacestodes (specifically $C$. tenuicollis and hydatid cyst) in the carcass and/or internal organs were examined, and the results/ findings were recorded. Particular attention was paid to the omentum, mesentery, peritoneal cavity, spleen, lung, and liver. The numbers and localizations of cysts were recorded.

\section{Data analysis}

Data were coded and entered into a Microsoft Office Excel (spreadsheet) and analyzed using Epi Info 7 software. The prevalence was computed as the proportion of sampled animals which harbor cysts. The Chi-square test was used to assess the statistical difference between proportions. Fisher's exact test was used when the number within categories were too small for the Chi-square. In all analyses, a critical probability of $\mathrm{p}<0.05$ was used for statistical significance.

\section{Results}

\section{Prevalence of metacestodes of Tenia and Echinococcus tapeworms}

The prevalence's of E. granulosus and T. hydatigena metacestodes in three slaughter slabs by species are as indicated in Table-1.

During postmortem examination, the larval form of $T$. hydatigena tape-worm (C. tenuicollis) was found attached to the mesenteries. The overall prevalence was $51.7 \%$ (95\% confidence interval [CI]: $44.11 \%, 59.16 \%$ ) and only $27.3 \%$ appeared as a single infection. The species prevalences were $61.1 \%$ and $42.2 \%$ in goats and sheep, respectively, as shown in Table-1. The prevalences in sheep and goats are statistically significant different $\left(\chi^{2}=6.35\right.$, $\mathrm{p}=0.011$ ).

Of 180 examined carcasses, $19.4 \% \quad(95 \%$ CI: $13.93 \%, 25.99 \%$ ) were infected by the larval form of E. granulosus (hydatid cyst) (Table-2), 16.6\% were found in sheep, and $22.2 \%$ in goats. $40 \%$ and $22.9 \%$, respectively, of the cysts were located only in the lungs and liver (Table-3). Concurrent infections were $25.7 \%$ in the liver and lungs; $2.9 \%$ in the lungs together with spleen and $8.6 \%$ in all three organs (liver, lungs, and spleen). No hydatid cysts were found in either the spleen or in the liver and spleen concurrently in sheep. The differences in the prevalence in the species and sex were both not statistically 


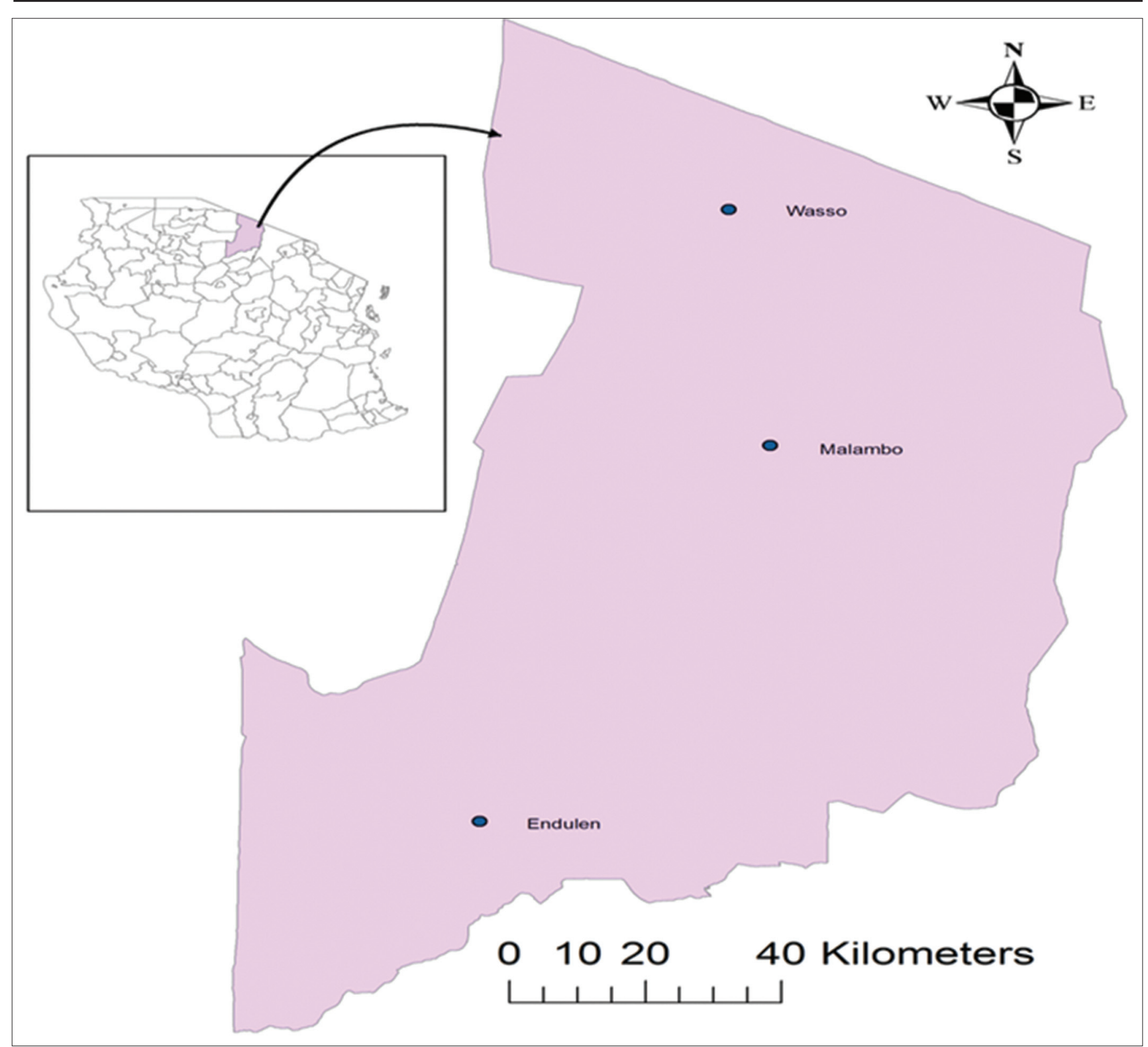

Figure-1: A map of Ngorongoro district showing the study villages. The insert is map of Tanzania.

Table-1: The prevalence (with exact $\pm 95 \%$ CIs) of C. tenuicollis cysts and hydatid cysts by species (January 2013-March 2013).

\begin{tabular}{|c|c|c|c|c|}
\hline \multirow[t]{2}{*}{ Species } & \multicolumn{2}{|c|}{ C. tenuicollis cysts } & \multicolumn{2}{|c|}{ Hydatid cyst } \\
\hline & Number positive & Prevalence $\%( \pm 95 \% \mathrm{CI})$ & Number positive & Prevalence \% ( $\% 95 \% \mathrm{CI})$ \\
\hline Ovine & 38 & $42.2(32.3-52.6)$ & 15 & $16.6(9.6-26.0)$ \\
\hline Caprine & 55 & $61.1(50.3-71.2)$ & 20 & $22.2(14.1-32.2)$ \\
\hline Overall & 93 & $51.7(44.1-59.1)$ & 35 & $19.4(13.9-25.9)$ \\
\hline
\end{tabular}

$\mathrm{CI}=$ Lower and upper limits for 95\% confidence interval of the prevalence, $\mathrm{C}$. tenuicollis=Cysticercus tenuicollis

significant being $\chi^{2}=0.82(\mathrm{p}=0.36)$ and $\chi^{2}=0.323$ $(\mathrm{p}=0.569)$, respectively.

\section{T. hydatigena infection}

The prevalence of $T$. hydatigena metacestodes in sheep and goats by sex, age and slaughter slab are shown in Table-2. Slaughtered sheep and goats in Malambo were consistently associated with high prevalence as compared to Waso and Endulen $(p<0.05)$. The variables of sex and age were not significantly associated with the prevalence of $C$. tenuicollis $(\mathrm{p}>0.05)$.

\section{Echinococcosis}

The prevalence of hydatid cysts in sheep and goats by sex, age and slaughter slab are detailed in Table-4. Significantly, higher prevalences were detected in Malambo slaughter slab $(p<0.05)$ for both species. In both animal species, age and sex were not significantly associated with prevalence $(\mathrm{p}>0.05)$. 
Table-2: Prevalences of T. hydatigena (C. tenuicollis) metacestodes in sheep and goats in three slaughter slabs ( $\mathrm{n}=90)$.

\begin{tabular}{|c|c|c|c|c|c|c|c|}
\hline Variable & Categories & No examined & $\begin{array}{c}\text { Proportion } \\
\text { examined (\%) }\end{array}$ & No positive & Prevalence (\%) & $\chi^{2}$ & p value \\
\hline \multicolumn{8}{|l|}{ Sheep } \\
\hline \multirow[t]{2}{*}{ Sex } & Male & 60 & 66.6 & 24 & 40 & 0.36 & 0.546 \\
\hline & Female & 30 & 33.4 & 14 & 46.7 & & \\
\hline \multirow[t]{3}{*}{ Slaughter slab } & Waso & 30 & 33.3 & 11 & 36.7 & 6.10 & 0.047 \\
\hline & Malambo & 30 & 33.3 & 18 & 60 & & \\
\hline & Endulen & 30 & 33.3 & 9 & 30 & & \\
\hline \multirow[t]{3}{*}{ Age } & $<1$ years & 14 & 15.5 & 5 & 35.7 & 0.306 & 0.858 \\
\hline & $>1-2$ years & 19 & 21.1 & 8 & 42.1 & & \\
\hline & $>2$ years & 57 & 63.3 & 25 & 43.8 & & \\
\hline \multicolumn{8}{|l|}{ Goats } \\
\hline \multirow[t]{2}{*}{ Sex } & Male & 41 & 45.5 & 8 & 19.5 & 0.32 & 0.572 \\
\hline & Female & 49 & 55.5 & 12 & 24.5 & & \\
\hline \multirow[t]{3}{*}{ Slaughter slab } & Waso & 30 & 33.3 & 5 & 16.7 & 8.61 & 0.013 \\
\hline & Malambo & 30 & 33.3 & 12 & 40 & & \\
\hline & Endulen & 30 & 33.3 & 3 & 10 & & \\
\hline \multirow[t]{3}{*}{ Age } & $<1$ years & 22 & 24.4 & 11 & 50 & 2.78 & 0.250 \\
\hline & $>1-2$ years & 20 & 22.2 & 15 & 75 & & \\
\hline & $>2$ years & 48 & 53.3 & 29 & 60.4 & & \\
\hline
\end{tabular}

T. hydatigena=Taenia hydatigena, $C$. tenuicollis=Cysticercus tenuicollis

Table-3: Prevalence and distribution pattern of hydatid cyst lesion in different organs in slab-slaughtered sheep $(n=90)$ and goats $(n=90)$ in Ngorongoro district.

\begin{tabular}{lccccc}
\hline Species & \multicolumn{5}{c}{ Organ location in percentage } \\
\cline { 2 - 6 } & Liver & Lungs & Liv\&lun & Lun\&spl & All \\
\hline Ovine & 20.0 & 46.7 & 26.7 & 0.0 & 6.7 \\
Caprine & 25.0 & 35.0 & 25.0 & 5.0 & 10.0 \\
Total & 22.9 & 40.0 & 25.7 & 2.9 & 8.6 \\
\hline
\end{tabular}

Liv\&lun - Liver and lungs, Lun\&spl - Lungs and spleen, All - Liver, lungs and spleen, Total - Sheep and goats

Mixed infections/coexistence rates of metacestodes

A total of $128(71.1 \%)$ carcasses were infected by different metacestodes ( 53 sheep and 75 goats). Of these, $11.5 \%(\mathrm{n}=15)$ were mixed infections (Table-5).

\section{Discussion}

Of 180 animals (90 sheep and 90 goats) examined in three slaughter slabs, $19.4 \%$ were found infected with hydatid cysts. This high prevalence was possibly because of the large dog population and the presence of other wild canids and the practice of home slaughter. Most of the slaughter slabs are not fenced and a dog helminth control strategy is not in place. Goats had the highest infection rate of $22.2 \%$ compared to $16.6 \%$ for sheep. However, the differences in species and by sex were not statistically significant, i.e. $\chi^{2}=0.82(\mathrm{p}=0.36)$ and $\chi^{2}=0.323(\mathrm{p}=0.569)$, respectively. The high prevalence found in goats recorded in this study is in agreement to the findings by Dalimi et al. [15] who reported a mean prevalence of $8.1 \%$ hydatidosis in sheep, $38.3 \%$ in goats in Iran and contrary to Oryan et al. [8] observation of $45.5 \%$, and $10.0 \%$ in sheep and goats, respectively in Fars, southern Iran. Similarly, the finding of this study is contrary to Nyero et al. [16] observation of $42.5 \%$, and $33.3 \%$ in sheep and goats, respectively, in Soroti, Uganda. The prevalence of hydatid cyst was higher in older sheep and goats $(19.3 \%$ and $29.1 \%$ in $>2$ and $>1-2$ years, respectively) compared to the younger ones and higher in male goats $(29.2 \%)$. This is in agreement with the study by Lahmar et al [17] in Tunisia and Helina [11] in Ethiopia who found higher prevalence in adult and males compared to young and female goats. Older animals have a more prolonged period of exposure and therefore much greater risk of infection and the chances of detecting cysts at meat inspection are higher in aged animals due to bigger size of the cysts [18]. Similarly, the previous studies strongly suggested that the prevalence is heavily influenced by age and origin of animals brought for slaughter $[17,19]$.

In this study, the observed overall prevalence of hydatid cysts in goats and sheep is lower than that observed in temperate countries, i.e., Italy where a prevalence of $47-81.9 \%$ in sheep and $71.9 \%$ in goats were reported [20]. Higher prevalences were also observed in Eastern Ethiopia and North West Iran $[21,22]$. Although specific reason for such variations was not clear, illegal slaughter and uncontrolled dog population and movement was postulated to play a role.

About $40 \%$ and $22.9 \%$ of the hydatid cysts were located only in one organ namely the lungs and liver, respectively. As in other previous studies by Getaw et al. [6] in Central Oromia, Ethiopia and Ibrahim [23] in Al Baha region, Saudi Arabia, the lungs and liver were the organs most commonly affected by hydatid cysts in sheep and goats. The respective concurrent organ infections were $25.7 \%$ in the liver and lungs; $2.9 \%$ in the lungs together with spleen and $8.6 \%$ in three organs (liver, lungs, and spleen). Fromsa and Jobre [24] in Ethiopia abattoirs obtained the prevalences of $11.78 \%$ in sheep and $4.9 \%$ in goats. The prevalence of hydatid cysts from this study was lower than the findings obtained of $63.8 \%$ 
Table-4: Prevalences of Echinococcus (hydatid cyst) metacestodes in sheep and goats in three slaughter slabs ( $\mathrm{n}=90$ )

\begin{tabular}{|c|c|c|c|c|c|c|c|}
\hline Variable & Categories & No examined & $\begin{array}{c}\text { Proportion } \\
\text { examined }(\%)\end{array}$ & No positive & Prevalence (\%) & $\chi^{2}$ & p value \\
\hline \multicolumn{8}{|l|}{ Sheep } \\
\hline \multirow[t]{2}{*}{ Sex } & Male & 60 & 66.6 & 10 & 16.7 & 0.02 & 1.00 \\
\hline & Female & 30 & 33.4 & 5 & 16.7 & & \\
\hline \multirow[t]{3}{*}{ Slaughter slab } & Waso & 30 & 33.3 & 5 & 16.7 & 7.68 & 0.021 \\
\hline & Malambo & 30 & 33.3 & 9 & 30 & & \\
\hline & Endulen & 30 & 33.3 & 1 & 3.3 & & \\
\hline \multirow[t]{3}{*}{ Age } & $<1$ years & 14 & 15.5 & 0 & 0 & 3.35 & 0.188 \\
\hline & $>1-2$ years & 19 & 21.1 & 4 & 21 & & \\
\hline & $>2$ years & 57 & 63.3 & 11 & 19.3 & & \\
\hline \multicolumn{8}{|l|}{ Goats } \\
\hline \multirow[t]{2}{*}{ Sex } & Male & 41 & 45.5 & 12 & 29.2 & 0.5 & 0.473 \\
\hline & Female & 49 & 54.4 & 8 & 16.3 & & \\
\hline \multirow[t]{3}{*}{ Slaughter slab } & Waso & 30 & 33.3 & 5 & 16.7 & 8.61 & 0.013 \\
\hline & Malambo & 30 & 33.3 & 12 & 40 & & \\
\hline & Endulen & 30 & 33.3 & 3 & 10 & & \\
\hline \multirow[t]{3}{*}{ Age } & $<1$ year & 22 & 24.4 & 1 & 4.5 & 3.82 & 0.148 \\
\hline & $>1-2$ years & 20 & 22.2 & 5 & 25 & & \\
\hline & $>2$ years & 48 & 53.3 & 14 & 29.1 & & \\
\hline
\end{tabular}

Table-5: Mixed infection rates of $C$. tenuicollis and hydatid cysts lesions in animals slaughtered at Ngorongoro district (January 2013-March 2013).

\begin{tabular}{lccc}
\hline Species & C. tenuicollis (\%) & $\begin{array}{c}\text { Hydatid } \\
\text { cysts (\%) }\end{array}$ & $\begin{array}{c}\text { C. tenuicollis } \\
\text { and hydatid } \\
\text { cysts (\%) }\end{array}$ \\
\hline Ovine & 42.2 & 16.6 & 9.4 \\
Caprine & 61.1 & 22.1 & 13.3 \\
Total & 51.7 & 19.45 & 11.5 \\
\hline
\end{tabular}

C. tenuicollis $=$ Cysticercus tenuicollis

in sheep and 34.7\% in goats by Ernest et al. [12] from Ngorongoro district. The differences may be attributed to the accuracy in the retrospective records and/or due to variations in the number of animals examined. However, in this study, the prevalence was higher than that reported by Nonga and Karimuribo [13] which was $6.02 \%$ in sheep and goats from Arusha. Although the prevalence was lower compared to the findings by Ernest et al. [25], still the prevalence suggests the possibility that hydatidosis is of public health importance in this study area and that some of the taeniid eggs recovered from the feces of dogs in the previous study may be eggs of Echinococcus species [26].

T. hydatigena metacestodes had the highest prevalence compared to those of Echinococcus spp. Out of the examined 90 sheep and 90 goats, the overall prevalence of $C$. tenuicollis was $51.7 \%$ and only $27.3 \%$ appeared as a single infection. Most of the cysticerci were found attached to the omentum or mesenteries.

The $C$. tenuicollis prevalence differences between sheep and goats were statistically significant $\left(\chi^{2}=6.35, p=0.011\right)$ with the prevalence having been observed to be higher in goats $(61.1 \%)$ compared to sheep $(42.2 \%)$. The reason for higher prevalence of C. tenuicollis in goats than in sheep is not known given the differences in feeding behavior of these two species, i.e., browsers and grazers, respectively. However, similar observations were also documented in other studies by Radfar et al. [27] who reported a prevalence of $12.87 \%$ in sheep and $18.04 \%$ in goats in Iran; Nimbakar et al. [28] (goats 34.2\% and sheep 21.4\%) in Maharashtra, India; Bayu et al. [19] (goats 15.8\% and sheep 7.81\%) in Ethiopia. Oryan et al. [8] recorded the prevalence of $17.52 \%$ in sheep and $55.05 \%$ in goats in Fars, Southern Iran and Singh et al. [29] reported a prevalence of $4.83 \%$ in goats compared to $2.23 \%$ in sheep. According to Torgerson et al. [10], under conditions of high infestation with $C$. tenuicollis, most sheep develop protective immunity early in life, whereas goats develop protective immunity more slowly. This considerable degree of immunity against C. tenuicollis in sheep may explain the reason for the low prevalence of the parasite in sheep.

The prevalence of $C$. tenuicollis in this study was also higher than the reports from other tropical countries in Africa. For instance, in Egypt, a prevalence of $34.5 \%$ of $C$. tenuicollis in sheep [30] was reported; in Nigeria, a prevalence of $21.4 \%$ in sheep and $34.2 \%$ in goats [31] were reported. In Iran, a prevalence of $34.2 \%$ in goats, $21.4 \%$ in sheep [32] was reported. The prevalence rate differences between studies could be due to the variation in temperature, environmental condition, the degree of pasture contamination because of uncontrolled dog movements and the way of raising and grazing of these animals that may contribute to the transmission cycle between ruminants, dogs and other wild canids. The grazing behavior and management can be considered as the major reasons for this regional difference. Uncontrolled dogs on grazing land as well as in the paddocks, add greatly to the prevalence of this parasite.

With regards to concurrent infections, the individual prevalence of hydatid and C. tenuicollis cysts was $9.4 \%$ and $23.3 \%$, respectively, suggesting that many slaughter ruminants are harboring multiple spp. indicating the need for routine de-worming against 
internal parasites. Collection of cysts to characterize etiology agent strain and to establish the viability and fertility of hydatid cysts were not determined due to logistic problems.

\section{Conclusion}

First and foremost, the study has shown that tapeworm metacestodes, particularly $C$. tenuicollis, and hydatid cysts are highly prevalent $(51.7 \%$ and $19.4 \%$, respectively) in Ngorongoro livestock-wildlife interface system, with small ruminants located in Malambo village presenting higher prevalence than in Waso and Endulen. Therefore, with regard to the high prevalence of Echinococcus and Taenia spp. metacestodes infections found, it is strongly recommended that the current status of hydatidosis infection in humans is properly investigated in the study area and that a joint one health solution on the risks posed by tapeworm infection is adopted.

\section{Authors' Contributions}

MBM (Livestock Office Ngorongoro) - conceive, design, collect data, analyze and prepared the manuscript. AAK (SUA Morogoro) provided guidance throughout the study period and prepared the manuscript. ESS (Directorate of Veterinary Services) was responsible for design, data analysis and preparation of the manuscript. All authors read and approved the final manuscript.

\section{Acknowledgments}

This work was done as part of broad Master of Science (MSc-Parasitology) undertaken at Sokoine University of Agriculture (SUA), Morogoro, Tanzania by the author MBM. We wish to express our deepest gratitude to the management of the slaughter slabs, owners of slaughter stock whose understanding and cooperation made this study a success. Very sincere gratitude and appreciation are extended to District Veterinary Officers for their invaluable support during the whole period of this study. Director of Veterinary Services is acknowledged for permission to publish this paper. The study was financially supported by IPBES Intergovernmental Platform on Biodiversity and Ecosystem Service, for which we are grateful.

\section{Competing Interests}

The authors declare that they have no competing interests.

\section{References}

1. URT (United Republic of Tanzania). (2012) National Sample Census of Agriculture 2007/2008 Small Holder Agriculture. Livestock Sector - National Report. Vol. III. National Bureau of Statistics, Dar es Salaam, Tanzania. p8-10.

2. Soulsby, E.J.L. (1986) Helminthes, Arthropods and Protozoa of Domesticated Animals. Vol. 7. Bailliere Tindall, London. p370-400.

3. Murell, K.D. (2005) Epidemiology of taeniosis and cysticercosis. Guidelines for the Surveillance, Prevention and
Control of Taeniosis/Cysticercosis WHO/FAO/OIE. OIE, Paris. p44.

4. Ahmadi, N.A. and Meshkehkar, M. (2011) An abattoir-based study on the prevalence and economic losses due to cystic echinococcosis in slaughtered herbivores in Ahwaz, SouthWestern Iran. J. Helminthol., 85(1): 33-39.

5. Gessese, A.T., Mulate, B. and Nazir, S. (2015) Major metacestodes in small ruminants slaughtered at Dessie municipal abattoir, Eastern Ethiopia: Prevalence, cyst viability, organ distribution and economic implications. Comp. Clin. Pathol., 24(3): 659-668.

6. Getaw, A., Beyene, D., Ayana, D., Megersa, B. and Abunna, F. (2010) Hydatidosis: Prevalence and its economic importance in ruminants slaughtered at Adama municipal abattoir, Central Oromia, Ethiopia. Acta Trop., 113: 221-225.

7. Dumitri, I.M., Dumitri, E. and Rugina, S. (2011) The role of epidemiologic data in management of hydatidosis in Constanta County, Romania. Ther. Pharmacol. Clin. Toxicol., 15(2): 132-138.

8. Oryan, A., Goorgipour, S., Moazeni, M. and Shirian, S. (2012) Abattoir prevalence, organ distribution, public health and economic importance of major metacestodes in sheep, goats and cattle in Fars, Southern Iran. Trop. Biomed., 29(3): 349-359.

9. Parija, S.C. (2004) Text Book of Medical Parasitology, Protozoology and Helminthology. India Publishers and Distributors, India, New Delhi. p2.

10. Torgerson, P.R., Williams, D.H. and Abo-Shehada, M.N. (2008) Modelling the prevalence of Echinococcus and Taenia species in small ruminants of different ages in Northern Jordan. Glob. Vet., 2(3): 92-145.

11. Helina, G., Tadesse, G., Tewodros, F. and Mersha, C. (2012) Small ruminants hydatidosis: Occurrence and economic importance in Addis Ababa abattoir. Glob. Vet., 8(2): 160-167.

12. Ernest, E., Nonga, H.E., Kassuku, A.A. and Kazwala, R.R. (2009) Studies on the epidemiology of echinococcosis/hydatidosis in Ngorongoro district, Arusha region, Tanzania. Trop. Anim. Health Prod., 41(7): 1179-1185.

13. Nonga, H.E. and Karimuribo, E.D. (2009) A retrospective survey of hydatidosis in livestock in Arusha, Tanzania, based on abattoir data during 2005-07. Trop. Anim. Health Prod., 41(7): 1253-1257.

14. Miran, B.M., Nzalawahe, J., Kassuku, A.A. and Swai, E.S. (2015) Prevalence of coenurosis in sheep and goats at three slaughter slabs in Ngorongoro district, Tanzania. Trop. Anim. Health Prod., 47(8): 1591-1597.

15. Dalimi, A., Motamedi, G., Hosseini, M., Mohammadian, B., Malaki, H., Ghamari, Z. and Ghaffari-Far, F. (2002) Echinococcosis/hydatidosis in Western Iran. Vet. Parasitol., 105: 161-171.

16. Nyero, D., Zirintunda, G., Omadang, L. and Ekou, J. (2015) Prevalence of hydatid cysts in goats and sheep in slaughtered in Soroti Municipal Abattoir, Eastern Uganda. Afr. $J$. Parasitol. Res., 2(9): 148-151.

17. Lahmar, S., Kilani, M., Torgerson, P.R., and Gemmell, M.A., (1999). Echinococcus granulosus larvae in the livers of sheep in Tunisia: The effects of host age. Ann. Trop. Med. Parasitol., 93:75-81

18. Pandey, V.S., Ohelli, H. and Moumen, A. (1988) Epidemiology of hydatidosis/echinococcosis in Quarzazte, the Pre-Saharan regions of Morocco. Ann. Rev. Trop. Med. Parasitol., 82(5): 461-470.

19. Bayu, Y., Asmelash, A., Zerom, K. and Ayalew, T. (2013) Prevalence and economic importance of liver parasites: Hydatid cyst, Fasciola species and Cysticercus tenuicollis in sheep and goats slaughtered at Addis Ababa abattoir enterprise in Ethiopia. J. Vet. Med. Anim. Health., 5(1): 1-7.

20. Grosso, G., Antonio, B., Marventano, S. and Mistretta, A. (2012) Worldwide epidemiology of liver hydatidosis including the Mediterranean area. World J. Gastroenterol., 
18(13): 1425-1437.

21. Daryani, A., Alaei, R., Arab, R., Sharif, M., Dehgham, M.H. and Ziaei, H. (2007) The prevalence, intensity and viability of hydatid cysts in slaughtered animals in the Ardabil Province of North West Iran. J. Helminthol., 81(3): 13-17.

22. Menkir, M.S., Uggla, A. and Waller, P.J. (2008) Prevalence and seasonal incidence of larval and adult cestode infections of sheep and goats in Eastern Ethiopia. Trop. Anim. Health Prod., 40(6): 387-394.

23. Ibrahim, M.M. (2010) Study of cystic echinococcosis in slaughtered animals in Al Baha region, Saudia Arabia: Interaction between some biotic and abiotic factors. Acta Trop., 113(1): 26-33.

24. Fromsa, A. and Jobre, Y. (2011) Infection prevalence of hydatidosis (Echinococcus granulosus, Batsch, 1786) in domestic animals in Ethiopia: A synthesis report of previous surveys. Ethiop. Vet. J., 15(2): 11-33.

25. Ernest, E., Kassuku, A. and Kazwala, R. (2004) Studies on the epidemiology of echinococcosis/hydatidosis in Ngorongoro district, Arusha region, Tanzania. Int. Arch Hydatid, 35: 43.

26. Swai, E.S., Miran, B.M., Kassuku, A.A. and Nzalawahe, J. (2016) Taeniasis in non-descript dogs in Ngorongoro, Tanzania: Prevalence and predisposing factors. Onderstepoort J. Vet. Res., 83(1): a1013.
27. Radfar, M.H., Tajalli, S. and Jalalzadeh, M. (2005) Prevalence and morphological characterization of Cysticercus tenuicollis (Taenia hydatigena cysticerci) from sheep and goats in Iran. Vet. Arh., 75(6): 469-476.

28. Nimbakar, R.K., Shinde, S.S., Kamtikar, V.N. and Muley, S.P. (2011) Study on Taenia hydatigena in the slaughtered sheep (Ovis bharal) and goats (Capra hircus) in Maharashtra, India. Glob. Vet., 6(4): 374-377.

29. Singh, B.B., Sharma, R., Gill, I.P.S. and Sharma, J.K. (2013) Prevalence and morphological characterisation of Cysticercus tenuicollis (Taenia hydatigena cysts) in sheep and goats in north India. J. Parasit. Dis., DOI: 10.1007/ s12639-013-0284-7.

30. Abu-Elwafa, S.A., Al-Araby, M.A. and Abbas, I.E. (2009) Metacestode among sheep slaughtered at Mansoura Abattoir, Dakahlia Province, Egypt. Vet. Med. J. Giza, 11(1), 21-23.

31. Nwosu, C.O., Ogunrinade, F. and Fagbemi, F. (1996) Prevalence and seasonal changes in gastro intestinal helminths of Nigerian goats. J. Helminthol., 70: 329-330.

32. Solaymani, M.S., Mobedi, I., Rezalan, M., Masauod, J., Mohebali, M., Hooshyar, H., Ashrafi, K. and Rokini, M.B. (2003) Helminth parasites of the wild boar, Sus scrofa in Luristan Province. J. Helminthol., 77: 263-267. 